\title{
Nunca tan a tiempo: acción colectiva y medios sociales en Latinoamérica
}

\author{
https://doi.org/10.1880o/conexion.202002.000
}

Nuevas formas de hacer política, de buscar apoyo, de coordinar acciones y de expresar puntos de vista vienen siendo desarrolladas en Latinoamérica por colectivos y movimientos, adolescentes y jóvenes, aunque también por ciudadanos y ciudadanas de mayor edad. Estos cambios no son producidos por las nuevas tecnologías, pero quienes los viven las usan como herramientas para ser más efectivos y tener más alcance. La forma como se apropian de estas tecnologías, que son parte indesligable de sus vidas y no algo «virtual», moldea sus vidas, percepciones, interrelaciones e interacciones, y puede encapsularlas o extenderlas (Gardner y Davis, 2013).

La marea verde -lucha por el aborto legal- en Argentina en 2018 o el estallido en Chile en 2019 no son casos aislados; es más, de aislados no tienen nada, ya que una de las características que podemos asignarles a estos movimientos es que son conectados. Se trata de un par de buenos ejemplos de los nuevos movimientos - ciclo mundial cuyo origen estaría situado en la Primavera Árabe (Castells, 2012; Postill, 2018) - que vemos en nuestro continente: integrados mayoritariamente por jóvenes, usuarios de los nuevos medios, capaces de integrar el humor y la performance en la acción política, mayormente horizontales, globalizados e hiperconectados, inclusivos y desafiantes. Puede ser que nuevamente haya un fantasma recorriendo Europa; a Latinoamérica la recorren jóvenes muy vivos buscando cambiar el mundo, y lo hacen usando medios sociales y celulares, lo que les es absolutamente natural.

Cuando decidimos lanzar este número de Conexión, estábamos convencidos de la importancia y actualidad del tema, pero nunca imaginamos que sería tan actual, presente e inmediato para quienes editamos este número en el Perú. Hace poco -entre el 10 y el 15 de noviembre de 2020-, una inmensa movilización popular, principalmente - pero 
no únicamente- juvenil, derribó al Gobierno impuesto por el Congreso tras dictaminarse la vacancia presidencial.

En septiembre, una moción de vacancia había fracasado al no alcanzar los votos necesarios. En octubre, se inició trámite a una nueva moción, que era rechazada por la mayoría de la población. Esta última aprobaba la presidencia de Vizcarra, no sin hacerle críticas, y consideraba un riesgo cambiar la conducción del país (Instituto de Estudios Peruanos, 2020a; Vila Benites y Bebbington, 2020). Mientras especialistas discutían en los medios de comunicación la legalidad del proceso, en los medios sociales se apuntaba a que este estaba movido por intereses personales. Sin embargo, el Congreso declaró la vacancia el lunes 9 de noviembre; al día siguiente, el presidente del Congreso, Manuel Merino, juró como presidente de la República.

Desde ese mismo día se empezó a movilizar el rechazo de la población al Gobierno de Merino. Hubo manifestaciones callejeras, críticas en algunos medios de comunicación (La República, 2020a; Rey, 2020) y estallaron las redes. Hashtags como \#MerinoNoEsMiPresidente y otros poblaron los medios sociales, y surgió allí mismo la convocatoria al primer cacerolazo para las 8 p. m. - modo de protesta apropiado a la condición de pandemia y aislamiento social-, que fue más fuerte en distritos de clase media. Al día siguiente, continuaron las movilizaciones y el cacerolazo se hizo más intenso, mientras el Gobierno no conseguía apoyo internacional ni formar un gabinete de ministros; se extendió la convocatoria a una gran movilización para el día siguiente (jueves 12). La movilización en espacios digitales continuaba aumentando: debates en Twitter; influencers adolescentes o juveniles apoyando las protestas; expresiones de soporte en ambientes de juego en línea; en plataformas usadas para esos juegos en línea, como Discord, se formaban grupos para discutir y organizar movilizaciones; en Facebook o Instagram, se publicaban gran cantidad de memes e invitaciones a protestar. Mientras tanto, Ántero Flores-Aráoz, nombrado primer ministro, trataba de conseguir ministros que lo acompañaran en su gabinete.

El 12 se dio una gran movilización. La principal se realizó en el Centro de Lima, y fue replicada en múltiples ciudades del resto del país y también en varios distritos de la capital. Ese día, el primer ministro conseguía finalmente, después de muchas tentativas, quienes aceptaran el 
cargo de ministro en un Gobierno ya muy cuestionado; no sorprende que muchos fueran muy criticados y otros, desconocidos. El rechazo al Gobierno de Merino era ya generalizado (Instituto de Estudios Peruanos, 2020b). Un nuevo protagonista en las redes fueron los $k$-popers, que anularon hashtags contrarios a las manifestaciones publicando fancams, tal como lo habían hecho en apoyo a \#BlackLivesMatter en Estados Unidos hace poco (Radio Programas del Perú, 2020a). La movilización principal y alguna de las otras fueron fuertemente reprimidas por la policía (Coordinadora Nacional de Derechos Humanos, 2020). Las imágenes de esta represión inundaron las redes y ampliaron el sentimiento de indignación; el cacerolazo de las 8 p. m. fue mayor en intensidad y alcance. Ese día, proliferaron las fake news, que ya habían aparecido en días anteriores, muchas orquestadas por el Gobierno o por quienes lo apoyaban para desprestigiar la protesta asociándola al terrorismo, pero también se extendió la «noticia» sobre un manifestante muerto, lo que luego fue desmentido.

El 13 de noviembre, la selección peruana de fútbol jugaba con la de Chile por las eliminatorias al mundial de fútbol, por lejos el deporte que mayor pasión y atención concita en la población. Tanto el Gobierno como muchos opinadores en medios esperaban una ralentización de la protesta. En cambio, en las redes le cambiaron de significado al hashtag \#PeruVsChile y a otros ligados al fútbol para difundir imágenes de la represión policial del día anterior y convocar a una nueva movilización para el día siguiente. Terminado el partido, tuvimos un cacerolazo mucho más extendido y algunas movilizaciones callejeras.

El 14, sucedió la más grande movilización en la historia del país; según una encuesta realizada el lunes siguiente, un $13 \%$ de la población participó en las marchas y un $73 \%$ dijo haberlas apoyado (Ipsos, 2020, p. 8). Varios centenares de miles de manifestantes salieron a las calles en todas las ciudades del Perú; el principal punto de encuentro fue el Centro de Lima, pero también hubo protestas en diversos barrios y distritos: cualquier plaza o parque era bueno para expresarse. Miles de carteles con lemas propios o ideas tomadas de internet; jóvenes disfrazados de sus personajes preferidos; performances y familias enteras marchando en múltiples ubicaciones producto de una coordinación sin dirigentes, completamente horizontal. Hasta que llegó la represión. Dos jóvenes murieron víctimas de disparos policiales, un centenar quedaron heri- 
dos y varias decenas habían desaparecido (Gestión, 2020a). A las 8 de la noche, el cacerolazo fue inmenso, y se repitió a las $10 \mathrm{p}$. m. tras la confirmación de la primera muerte y a la medianoche luego de la segunda. Muchos, entre tristes, rabiosos y azorados, no pudimos dormir y nos quedamos siguiendo las redes y los informativos hasta altas horas de la madrugada. A lo largo de esta, se fueron sucediendo las renuncias de los ministros. Debemos anotar que, además de la difusión de noticias, también circulaban rumores luego desmentidos o fake news que daban cuenta de mayores cifras de muertos y heridos.

El domingo 15, el Congreso se reunía - a distancia- de urgencia. Merino, después de la renuncia de la inmensa mayoría de sus ministros, y de recibir el desprecio de las Fuerzas Armadas (La República, 202od; Radio Programas del Perú, 2020b) y hasta el rechazo de su propio partido político (La República, 2020b) y del gremio empresarial (CONFIEP, 2020; La República, 2020c), se vio obligado a renunciar «irrevocablemente» al mediodía (Andina, 2020). En ese momento, volvieron los cacerolazos y ocurrieron inmediatamente celebraciones callejeras.

Podríamos decir que esta movilización fue «de libro»: una multitud inteligente (Rheingold, 2002/2004); autoorganizada, horizontal, espontánea y movida por sentimientos (Castells, 2012); creativa y transmedia (Jenkins et al., 2016); surgida para responder a oportunidades y restricciones (Tarrow, 1994/2012; Tilly y Tarrow, 2006); y sucedida en un espacio híbrido físico y digital (Bennett y Segerberg, 2012; Castells, 2012; Postill, 2018). En cuanto a repertorios, esta acción colectiva fue performática (Castro Pérez, 2019; Fuentes, 2019) y dio espacio al humor y al activismo lúdico (Treré, 2015); las expresiones en las calles y las redes estaban ligadas a la cultura mediática y global (Castro Pérez, 2019); contó con el activismo de fans (Jenkins, 2012; Kligler-Vilenchik, 2016). Se buscó ser tendencia en redes (Castro Pérez, 2019) y estas se usaron en y para la protesta (Gerbaudo, 2012). Hubo aquí adaptación y apropiación de tecnologías (Walsham, 2001). Entre sus participantes, se generó identidad (Treré, 2015), con la conciencia de que no estar afiliados a partidos no implicaba que fuesen apolíticos (Cano-Correa et al., 2017; García-Canclini, 2020); forjaron decenas de canales en múltiples plataformas para comunicarse, coordinar y solidarizarse (Treré, 2015). 
Esta movilización combinó varias acciones y repertorios, unos a partir de la experiencia acumulada - para la juventud de ahora, desde la lucha contra la llamada ley pulpín, contraria a derechos laborales, en 2014; para la juventud de antes, desde la lucha contra Fujimori en la década de los noventa- $y$ otros aprendidos de movilizaciones en otros países. Esto último convierte a esta movilización en la más globalizada que haya existido en el Perú, lo que no quita que haya habido conexión $\mathrm{y}$ aprendizaje internacional en movilizaciones anteriores, especialmente en el feminismo y el movimiento LGBT, pero también en ecologistas, animalistas y, por qué no mencionarlo, en movimientos reaccionarios como los opuestos al aborto o al enfoque de género en la educación.

Esta movilización aprendió de la de hace un año en Chile a ocupar distintos espacios en la ciudad para así dividir la represión y también a desactivar bombas lacrimógenas, no por la lectura de manuales o estudios, sino por contactos con jóvenes del sur y videos en YouTube. Utilizó la recientemente famosa táctica k-poper de desnaturalizar hashtags, no porque algunos jóvenes guardaran en la memoria artículos periodísticos sobre el tema, sino por la conexión entre los k-popers peruanos y quienes arruinaron el hashtag \#WhiteLivesMatter en defensa de \#BlackLivesMatter (Radio Programas del Perú, 2020a). Durante esta movilización, llegó para quedarse el repertorio del escrache, desarrollado por movimientos de derechos humanos en Argentina y consistente en movilizarse a la puerta de la casa personal del político repudiado (Taylor, 2003/2016). Muchos comentarios y publicaciones en redes dieron cuenta -muchas veces de manera irónica- de la dirección de los domicilios del primer ministro y de otros miembros del Gobierno. Al escrache a personalidades o la movilización contra instituciones se sumó la proyección a distancia de consignas usando equipos para video mapping, lo que pudo haberse copiado de la movilización chilena, aunque ha sucedido en pandemia en otros lugares en Latinoamérica, como Costa Rica y Argentina. Desde la movilización se buscó a Anonymous -o sus miembros en la movilización lo hicieron- y se bloquearon páginas web públicas, como la del Congreso.

Otras prácticas que ya estaban en uso se desarrollaron más, tales como los letreros que dan cuenta de la opinión -a veces en clave humorística- de quien lleva el cartel y no de una organización o partido, el uso de performances y otras representaciones artísticas, la denuncia/ 
bloqueo de enemigos en redes sociales - conocida como escrache digital-, el uso de memes en el debate político, la producción de hashtags convocantes o atractivos, o el registro gráfico de las ocurrencias de la movilización y su comunicación por redes. El cacerolazo ya había sido usado, aunque no tanto como en otros países -Argentina, por ejemplo-, de los que debe de venir el nombre, ya que en el Perú llamamos olla a los recipientes usados para cocinar; lo nuevo fue su registro y transmisión en vivo por redes.

No he descubierto cómo rastrear el origen de otras novedades, pero, sin duda, tiene que ver con el uso de medios digitales. Tuvimos en las grandes movilizaciones escuadrones autoorganizados como primera línea, desactivadores de bombas o ayuda de emergencia, y muchos de los manifestantes eran parte de cadenas informáticas de seguridad y rastreo organizadas por sindicatos de estudiantes o por los mismos asistentes, replicadas por la Coordinadora Nacional de Derechos Humanos para identificar casos de desaparecidos (Gestión, 2020b).

Luego de conseguido el cambio buscado, se le ha venido dando continuidad al sentimiento de identidad y al movimiento mediante actividades político-culturales como altares de homenaje, murales y presentaciones artísticas. Es más, acciones contrarias de grupos opuestos - presumiblemente fujimoristas- y de la policía no han hecho sino impulsar la reproducción de nuevos altares y murales.

Poco después, a fines de noviembre, una nueva movilización -más sectorial y localizada- consiguió la derogación de la Ley de Promoción Agraria, la cual reducía derechos laborales e ingresos a los trabajadores en el «exitoso» - para los empresarios- sector agroexportador. Sin duda, los movimientos protagonizados por trabajadores agrícolas están desde el origen de las acciones colectivas y movimientos sociales hace varios siglos. Lo que ha impulsado esta movilización ha sido la lucha por lo que denominamos derechos primarios - trabajo e ingresos dignos-, no cuestiones de identidad, reconocimiento o expresión, como el caso de los movimientos juveniles urbanos y globalizados mencionados antes, y que inspiran los artículos de este número. Sin embargo, no cabe duda de que la movilización contra la Ley de Promoción Agraria fue animada por la victoria del movimiento democrático y de que se ha nutrido de este en repertorios. Por ejemplo, se sabe que las 
movilizaciones fueron también convocadas y coordinadas en grupos de Facebook, además de en los espacios físicos en que estos trabajadores coinciden durante el día. Adicionalmente, se han visto en imágenes carteles hechos desde la experiencia individual de los manifestantes; muchos trabajadores son jóvenes habitantes de ciudades pequeñas y medianas que han estado en ambos movimientos. Tampoco podemos dejar de mencionar que parte importante de los jóvenes y colectivos presentes en las movilizaciones de mediados de noviembre manifestaron su apoyo a los agricultores en redes, así como la circulación de historias e imágenes propaladas por jóvenes de sectores urbanos que pasaron por la experiencia de trabajar un tiempo en la agroexportación.

Más allá de todo lo dicho aquí, este número de Conexión no puede tratar en detalle esa semana en que la juventud sacudió el poder en el Perú, menos aún lo que sigue sucediendo. Los artículos los recibimos hasta abril; ya estábamos en crisis política, pero esta era en las alturas. Nuestro subsiguiente número incluirá entre sus temas el análisis de los hechos recientes. Los y las invito a visitar la convocatoria.

Este número de Conexión sobre acción colectiva y medios sociales es variado en perspectivas, alcances, estilos y enfoques metodológicos. Contiene artículos con una visión general y estudios de caso que tratan diversos repertorios y espacios digitales. Además, sus autores y autoras residen en ocho países distintos: Argentina, Chile, Bolivia, el Perú, Ecuador, México, Estados Unidos e Inglaterra. Pero tiene tendencias y mayorías claves. Todos sus artículos están escritos desde un interés por la transformación social, la cual tiene distintas definiciones, pero no es conservadora. La mayor parte de los estudios de caso abordan luchas o espacios feministas, lo que no extraña dada la importancia de este movimiento a nivel global y dado que fue de los primeros en apropiarse de internet (Gajjala y Oh, 2012). Sin embargo, debemos aclarar que, cuando abrimos la convocatoria de este número, invitamos también análisis de acciones o movimientos desde la reacción o el conservadurismo, como Con Mis Hijos No Te Metas (CMHNTM), opuestos a la implementación del enfoque de género en la educación escolar. Lamentablemente, no recibimos propuestas que trataran este tipo de movimientos o acciones colectivas. 
Hemos dividido los artículos que presentamos en tres secciones. En la primera, llamada «Política y comunicación en tiempos de los medios sociales», incluimos dos artículos con una perspectiva general respecto a los cambios en la acción política y la comunicación en la actualidad. Luego, agrupada bajo el título «Memes, lenguajes, comentarios y hashtags: repertorios digitales en Latinoamérica», viene una sección con cuatro estudios de caso - dos de México, uno de Ecuador y otro de Bolivia - que tratan sobre distintos repertorios y acciones. Por último, la sección «Juntas somos más fuertes: sororidad en espacios digitales feministas» refleja la experiencia de dos casos de grupos feministas peruanos en Facebook. A continuación, presento todos los artículos en orden de aparición.

En «\#Cultura digital: reflexiones en torno a los consumos políticos contemporáneos», Lucrecia Taricco y A. Pamela Paz García debaten sobre prácticas culturales de consumo digital en el contexto de la vida cotidiana, analizando una serie de fenómenos dentro de la práctica de la comunicación política, como las fake news, la privacidad de datos personales y las redes sociales. Emparentado con esta temática está el análisis de Paul Maquet Makedonski Valdeavellano: «Euforia y pesimismo en tiempos de internet. Hacia una relectura de los efectos políticos de los medios sociales a la luz de las mediaciones». Él encuentra que una serie de fenómenos, tales como las cámaras de eco, la radicalización y la posverdad, pueden llevarnos a dudar de que el uso de tecnologías tenga un poder transformador positivo, pero que esta percepción se debe a que se le da un rol determinante a la tecnología.

El primero de nuestros casos proviene de Bolivia. En su artículo «Memes de internet como reforzadores de identidades políticas: estudio de caso de la crisis sociopolítica boliviana de 2019», Nicolás Ewel y Carlo Piérola describen la forma como los distintos sectores envueltos en la disputa previa a la caída de Evo Morales usaron este recurso en la batalla política.

En el siguiente, «El discurso del movimiento LGBTI en Ecuador: usos del lenguaje y la tecnología en momentos de campaña electoral», Marcelo Criollo Burbano analiza estrategias comunicacionales digitales de colectivos LGBTI durante la campaña electoral ecuatoriana de 2017 considerando las expresiones, los estilos y los espacios discursivos que usan. 
Los que siguen tratan el mismo caso: la movilización feminista \#8M en México este año 2020. Ambos son también cuantitativos, aunque el objeto y la relación que estudian sean distintos. Por un lado, «La protesta feminista \#8M 2020 en México a través de la participación de comentarios en YouTube», de Lidia A. García-González y Olga Bailey Guedes, tiene como corpus los comentarios generados y publicados los días 8 y 9 de marzo sobre la marcha \#8M en Ciudad de México; encuentran en su análisis mucho debate, misoginia y ciberviolencia de género. Por otro lado, en «Acciones feministas en red: análisis del hashtag \#Marcha8M en México», Raul Anthony Olmedo Neri analiza la red generada alrededor del hashtag \#Marcha8M mediante el método de análisis de redes sociales (ARS), lo que permite identificar los nodos más importantes y las funciones que cumplen en el establecimiento de relaciones, análisis que se muestra útil para otros casos y fenómenos similares.

Característica de muchos movimientos actuales es estar aglutinados por un sentimiento. Desde este sentimiento se producen el dolor, el reclamo, la acción, la lucha y la esperanza. Se trata de movimientos identitarios, lo que incluye desde aquellos que se agrupan por identidad de gustos o quehaceres hasta aquellos en que la identidad en disputa es constitutiva de su ser. El feminismo es, al mismo tiempo, un movimiento político-ideológico y un movimiento identitario; para las militantes, el ser feminista es parte de su cotidianidad, de su ser y estar en el mundo. En la raíz de la naturaleza identitaria del feminismo, están, entre otros aspectos, la experiencia de violencia que sufren las mujeres y la sororidad que practican entre ellas. De estos temas tratan, a partir de distintos casos y desde diferentes perspectivas, los trabajos de Valeria Soto Canales, «La comunicación para el cambio social y el proceso de empoderamiento en una comunidad virtual: el caso del grupo de Facebook Ni Una Menos: Movilización Nacional Ya», e Illari Diez, «Construyendo seguridad para la manifestación de la sororidad desde \#LasRespondonas».

Además de los artículos académicos mencionados, agregamos a este número de Conexión un ensayo y una reseña.

Ricardo Gómez nos trae en su ensayo una visión crítica tanto de lo que ha traído el desarrollo de las tecnologías y su apropiación social como de las visiones de quienes trabajábamos en TIC para el desarrollo hace 
20 años o más. En la década de los noventa, teníamos, por un lado, a quienes auguraban extraordinarios y siempre positivos cambios gracias al avance de las TIC, y, por otro, a quienes descreían de estas o solo les veían impactos productivos u organizacionales; en el medio, o en uno de los medios posibles, algunos sosteníamos que las tecnologías podían tener un poder transformador si contaban para ello con la participación activa de las comunidades y perspectivas de género, generación y cultura. No digo que estuviéramos equivocados, pero es cierto que algunos de los cambios sociotecnológicos que vinieron nos pasaron por encima. De dichos cambios trata el ensayo de Ricardo «Veinte años después, una respuesta a la Carta a la Tía Ofelia».

En «Los nerds de la política bajo la lupa», Roberto Bustamante Vento presenta The Rise of Nerd Politics: Digital Activism and Political Change, de John Postill. No solo comenta sus principales conceptos y sus fuentes, sino que plantea interrogantes a partir de estos para nuestro contexto, en una invitación a la lectura claramente situada aquí y ahora.

Por último, quiero dedicar mi trabajo de edición de este número de Conexión y esta presentación a la memoria de mi tía Zita Montes de $\mathrm{Oca}^{1}$, primera feminista que conocí usando políticamente internet en la década de los noventa - utilizando un módem para descargar correos electrónicos-, y a la de mi amiga Cecilia Fernández, ingeniera convencida del poder transformador de las TIC usadas participativamente en y desde las comunidades.

Juan Fernando Bossio

Editor temático del número 14 de Conexión

Departamento Académico de Comunicaciones

Pontificia Universidad Católica del Perú 


\section{REFERENCIAS}

Andina. (2020, 15 de noviembre). Manuel Merino renuncia a la presidencia de la República. https://andina.pe/agencia/noticia-manuel-merino-renuncia-a-presidencia-de-republica-821561.aspx

Bennett, W. L. y Segerberg, A. (2012). The logic of connective action: Digital media and the personalization of contentious politics. Information, Communication \& Society, 15(5), 739-768. https://doi.org/10.1080/1369118X.2012.670661

Cano-Correa, A.-M., Quiroz-Velasco, M.-T. y Nájar-Ortega, R. (2017). Jóvenes universitarios en Lima: Política, medios y participación. Comunicar, 25(53), 71-79. https://doi.org/10.3916/C53-2017-07

Castells, M. (2012). Redes de indignación y esperanza. Los movimientos sociales en la era de Internet (Trad. M. Hernández). Alianza Editorial.

Castro Pérez, R. (2019). «Quería probar que puedo hacer tendencia». Activismos ciudadanos online y prácticas poplíticas en el Perú. Anthropologica, 37(42), 177-200. https://doi.org/10.1880o/anthropologica.201901.008

Coordinadora Nacional de Derechos Humanos. (2020). Protestas en Perú - Principales temas de preocupación al 12/11. https://derechoshumanos.pe/ wp-content/uploads/2020/11/Derechos_en_protesta_111120.pdf

CONFIEP. (2020, 15 de noviembre). Acuerdo de Directorio de CONFIEP frente a la coyuntura de crisis política que vive el país. https://www.confiep.org. pe/noticias/destacado/comunicado-3/

Fuentes, M. A. (2019). Performance constellations: Networks of protest and activism in Latin America. University of Michigan Press. https://doi. org/10.3998/mpub.8172441

Gajjala, R. y Oh, Y. J. (Eds.). (2012). Cyberfeminism 2.o. Peter Lang Publishing.

García Canclini, N. (2020, 10-12 de diciembre). Públicos de la cultura en tiempos de pandemia y transformación digital [Panel]. Encuentro Conecta 2020. Públicos digitales: nuevos escenarios para la participación cultural, Ministerio de Cultura del Perú. https://www.facebook.com/cultura24.tv/videos/505241433728129/

Gardner, H. E. y Davis, K. (2013). The app generation: How today's youth navigate identity, intimacy, and imagination in a digital world. Yale University Press.

Gerbaudo, P. (2012). Tweets and the streets: Social media and contemporary activism. Pluto Press. https://doi.org/10.2307/j.ctt183pdzs

Gestión. (2020a, 15 de noviembre). Coordinadora de Derechos Humanos alerta que hay 41 jóvenes que aún no han sido ubicados. https://gestion.pe/peru/politica/coordinadora-de-derechos-humanos-alerta-que-hay-41-jovenes-que-aun-no-han-sido-ubicados-nndc-noticia/ 
Gestión. (2020b, 15 de noviembre). CNDDHH habilita registro online para monitorear situación de desaparecidos durante marcha. https://gestion. pe/peru/cnddhh-habilita-documento-online-para-monitorear-situacion-de-40-desaparecidos-durante-marcha-contra-merino-nndc-noticia/

Instituto de Estudios Peruanos. (2020a, octubre). IEP Informe de Opinión - Octubre 2020. Encuesta telefónica a nivel nacional. https://iep.org.pe/ wp-content/uploads/2020/10/Informe-IEP-OP-Octubre-2020-4.pdf

Instituto de Estudios Peruanos. (2020b, noviembre). IEP Informe de Opinión Noviembre 2020. Encuesta telefónica a nivel nacional. https://iep.org. $\mathrm{pe} / \mathrm{wp}$-content/uploads/2020/11/Informe-Especial-IEP-OP-Noviembre-2020-v2.pdf

Ipsos. (2020). La Crisis Política en el Perú. Noviembre 2020. https://www.ipsos. com/sites/default/files/ct/news/documents/2020-11/la_crisis_politica_noviembre_2020.pdf

Jenkins, H. (2012). «Cultural acupuncture»: Fan activism and the Harry Potter Alliance. Transformative Works and Cultures, 10. https://doi. org/10.3983/twc.2012.0305

Jenkins, H., Shresthova, S., Gamber-Thompson, L., Kligler-Vilenchik, N. y Zimmerman, A. (2016). By any media necessary: The new youth activism. New York University Press.

Kligler-Vilenchik, N. (2016). «Decreasing world suck»: Harnessing popular culture for fan activism. En H. Jenkins, S. Shresthova, L. Gamber-Thompson, N. Kligler-Vilenchik y A. Zimmerman, By any media necessary: The new youth activism (pp. 102-148). New York University Press.

La República. (2020a, 10 de noviembre). Golpe de Estado [Editorial]. https:// larepublica.pe/opinion/2020/11/10/golpe-de-estado-editorial/

La República. (2020b, 14 de noviembre). Presidente de Acción Popular, Mesías Guevara: «Manuel Merino debería renunciar». https://larepublica. pe/politica/2020/11/14/presidente-de-accion-popular-mesias-guevara-manuel-merino-deberia-renunciar/

La República. (2020c, 15 de noviembre). Confiep retrocede y pide la renuncia de Manuel Merino. https://larepublica.pe/economia/2020/11/15/confiep-retrocede-y-pide-la-renuncia-de-manuel-merino/

La República. (2020d, 15 de noviembre). Fuerzas Armadas anuncia su respaldo y defensa a la población. https://larepublica.pe/politica/2020/11/15/ fuerzas-armadas-anuncia-su-respaldo-y-defensa-a-la-poblacion/

Postill, J. (2018). The rise of nerd politics: Digital activism and political change. Pluto Press.

Rey, A. (2020, 10 de noviembre). Golpe, es un golpe. Perú21. https://peru21.pe/ opinion/golpe-es-un-golpe-augusto-rey-noticia/ 
Rheingold, H. (2004). Multitudes inteligentes: la próxima revolución social (Trad. M. Pino Moreno). Gedisa. (Trabajo original publicado en 2002)

Radio Programas del Perú. (2020a, 12 de noviembre). Fans del K-Pop se adueñan de hashtag que condenaba las protestas contra Manuel Merino. https:// rpp.pe/tecnologia/redes-sociales/twitter-fans-del-k-pop-se-aduenan-de-hashtag-que-condenaba-las-protestas-contra-manuel-merino-noticia-1303825?ref=rpp

Radio Programas del Perú. (2020b, 15 de noviembre). Comandantes de las Fuerzas Armadas no asistieron a reunión citada por el presidente Manuel Merino. https://rpp.pe/politica/gobierno/comandantes-de-las-fuerzas-armadas-no-asistieron-a-reunion-citada-por-el-presidente-manuel-merino-noticia-1304352

Tarrow, S. G. (2012). El poder en movimiento. Los movimientos sociales, la acción colectiva y la política (Trad. F. Muñoz de Bustillo; $3 \cdot{ }^{\mathrm{a}}$ ed.). Alianza Editorial. (Trabajo original publicado en 1994)

Taylor, D. (2016). El archivo y el repertorio: el cuerpo y la memoria cultural en las Américas (Trad. A. Contreras Castro). Ediciones Universidad Alberto Hurtado. (Trabajo original publicado en 2003)

Tilly, C. y Tarrow, S. G. (2006). Contentious politics. Paradigm Publishers.

Treré, E. (2015). Reclaiming, proclaiming, and maintaining collective identity in the \#YoSoy132 movement in Mexico: An examination of digital frontstage and backstage activism through social media and instant messaging platforms. Information, Communication \& Society, 18(8), 901-915. https://doi.org/10.1080/1369118X.2015.1043744

Vila Benites, G. y Bebbington, A. (2020). La democracia peruana afronta su mayor desafio desde la dictadura de Fujimori. The Conversation. https:// theconversation.com/la-democracia-peruana-afronta-su-mayor-desafio-desde-la-dictadura-de-fujimori-151326

Walsham, G. (2001). Making a world of difference: IT in a global context. Wiley. 